\title{
Catheter mapping of retrograde atrial activation Observations during ventricular pacing and AV nodal re-entrant paroxysmal tachycardia ${ }^{1}$
}

\author{
Fernando Amat-y-Leon, Ramesh C. Dhingra, Delon Wu, Pablo Denes, Christopher Wyndham, \\ and Kenneth M. Rosen \\ From the Cardiology Sections of the West Side Veterans' Administration Hospital, and the Abraham Lincoln \\ School of Medicine, University of Illinois College of Medicine, Chicago, Illinois, U.S.A.
}

\begin{abstract}
A systematic study of retrograde atrial activation sequence at commonly used electrode catheter recording sites in 8 patients without, and in 4 patients with AV nodal re-entrant paroxysmal tachycardia was made. During right ventricular pacing, the retrograde atrial activation sequence was low septal right atriumproximal coronary sinus-distal coronary sinus-high right atrium. During the episodes of paroxysmal tachycardia, a similar pattern was observed. This information should be helpful in the understanding of abnormal activation sequences in patients with paroxysmal supraventricular tachycardia in whom retrogradely conducting anomalous pathways are suspected.
\end{abstract}

Electrophysiological studies in the catheterization laboratory have contributed significantly to the understanding of mechanisms of paroxysmal supraventricular tachycardia. One group of patients with paroxysmal tachycardia is characterized by the presence of anomalous pathways, either manifest or concealed (Durrer and Wellens, 1974; Coumel and Attuel, 1974; Spurrell, Krikler, and Sowton, 1974a; Neuss, Schlepper, and Thorman, 1975; Zipes, DeJoseph, and Rothbaum, 1974). In these patients, the anomalous pathway usually constitutes the retrograde limb of an atrioventricular circus movement during paroxysmal tachycardia. Documentation of the presence of a retrogradely conducting anomalous pathway is dependent upon demonstration of abnormal retrograde activation sequences, during both ventricular pacing and paroxysmal tachycardia (Wellens and Durrer, 1974; Svenson et al., 1974; Wellens, 1975; Denes et al., 1975; Gallagher et al., 1975). For example, retrograde activation of the atria via a left lateral Kent bundle should produce early activation of the left atrium, as recorded from a catheter placed in the distal coronary sinus.

Received 26 August 1975.

1 Supported in part by a USPHS training grant, NIH contract, new NIH grant, and the West Side Veterans' Administration Hospital, Chicago Basic Institutional Support.
Despite the obvious usefulness of catheter electrode atrial mapping during retrograde activation, there has been no systematic study of normal retrograde activation via the $\mathrm{His}$ bundle and $\mathrm{AV}$ node, with commonly used electrode catheter recording sites. Without a clear picture of what normal activation is like, demonstration of 'abnormal sequences' is of questionable meaning. In this study we have attempted to define the normal pattern of retrograde activation of the atria with commonly used catheter electrode positions in patients with and without AV nodal re-entrant paroxysmal tachycardia. This information should be extremely helpful in analysis of patients with paroxysmal tachycardia in whom retrogradely conducting anomalous pathways are suspected.

\section{Methods}

The study group consisted of 12 patients with intact AV conduction undergoing electrophysiological evaluation. Group 1 consisted of 8 patients with suspected or proven conduction disease, who were classified as having normal VA conduction. These patients fulfilled the following criteria: 1) no previous history of palpitations or paroxysmal tachycardia; 2) absence of manifest antegrade pre-excitation determined by the evaluation of standard 12-lead electrocardiograms; 3) evidence of retrograde AV nodal conduction (without evidence of retrograde 
TABLE 1 Clinical, electrocardiographic, and electrophysiological findings in 12 patients

\begin{tabular}{|c|c|c|c|c|c|c|c|c|c|c|c|c|c|}
\hline $\begin{array}{l}\text { Case } \\
\text { No. }\end{array}$ & $\begin{array}{l}\text { Age } \\
\text { (yr) }\end{array}$ & Sex & $\begin{array}{l}\text { Clinical } \\
\text { diagnosis }\end{array}$ & \multicolumn{2}{|c|}{$\begin{array}{l}\text { Electrocardiogram } \\
P R(s) Q R S(s)\end{array}$} & \multicolumn{6}{|c|}{$\begin{array}{l}\text { Electrophysiological findings during sinus rhythm } \\
\text { (ms) }\end{array}$} & \multicolumn{2}{|c|}{$F R P-A E R P-A$} \\
\hline \multicolumn{14}{|c|}{ Group 1} \\
\hline 1 & 24 & $\mathbf{M}$ & NHD & $0 \cdot 14$ & 0.08 & 81 & 38 & 92 & 55 & 660 & 630 & 400 & 380 \\
\hline 2 & 57 & $\mathbf{M}$ & VHD & $0 \cdot 16$ & 0.08 & 62 & 45 & 79 & 47 & 400 & 320 & 300 & 220 \\
\hline 3 & 63 & $\mathbf{M}$ & SSS & $0 \cdot 20$ & 0.08 & 86 & 42 & 96 & 50 & 530 & 400 & 300 & 210 \\
\hline 4 & 52 & M & ASHD & $0 \cdot 14$ & $0.08(\mathrm{LVH})$ & 92 & 44 & 89 & 40 & 390 & $<360$ & 360 & 290 \\
\hline 5 & 34 & F & $\begin{array}{r}\text { Sarcoi- } \\
\text { dosis }\end{array}$ & $0 \cdot 14$ & 0.08 & 97 & 35 & 87 & 34 & 320 & $<250$ & 250 & 230 \\
\hline 6 & 57 & $\mathbf{M}$ & ASHD & $0 \cdot 16$ & 0.08 & 53 & 43 & 120 & 40 & 450 & 340 & 340 & 240 \\
\hline 7 & 64 & $\mathbf{M}$ & ASHD & $0 \cdot 18$ & 0.12 (RBBB \& LASH) & 90 & 42 & 76 & 86 & 330 & $<310$ & 310 & 280 \\
\hline 8 & 81 & $\mathbf{M}$ & ASHD & $0 \cdot 24$ & $0 \cdot 12$ (RBBB \& LASH) & 64 & 59 & 145 & 65 & 665 & 450 & 280 & 230 \\
\hline \multicolumn{14}{|c|}{ Group 2} \\
\hline 9 & 25 & $\mathrm{~F}$ & NHD & $0 \cdot 14$ & 0.08 & 91 & 41 & 58 & 35 & $\begin{array}{l}S=545 \\
F=340\end{array}$ & $\begin{array}{l}S=<250 \\
F=260\end{array}$ & 250 & 180 \\
\hline 10 & 53 & $\mathbf{M}$ & ASHD & $0 \cdot 18$ & $0.08(\mathrm{LVH})$ & 99 & 26 & 122 & 54 & $\begin{array}{l}S=470 \\
F=410\end{array}$ & $\begin{array}{l}\mathrm{S}=<310 \\
\mathrm{~F}=350\end{array}$ & 310 & 280 \\
\hline 11 & 55 & $\mathbf{M}$ & NHD & $0 \cdot 16$ & 0.08 & 62 & 40 & 87 & 55 & $\begin{array}{l}S=520 \\
F=425\end{array}$ & $\begin{array}{l}S=285 \\
F=350\end{array}$ & 260 & 240 \\
\hline 12 & 77 & $\mathbf{M}$ & HCVD & $0 \cdot 16$ & $0.08(\mathrm{LVH})$ & 96 & 50 & 91 & 49 & $\begin{array}{l}S=440 \\
F=330\end{array}$ & $\begin{array}{l}\mathrm{S}=<250 \\
\mathrm{~F}=280\end{array}$ & 250 & 180 \\
\hline
\end{tabular}

Abbreviations : $\mathrm{NHD}=$ No organic heart disease; $\mathrm{VHD}=$ valvular heart disease; $\mathrm{SSS}=$ sick sinus syndrome; $\mathrm{ASHD}=$ arteriosclerotic heart disease; $H C V D=$ hypertensive cardiovascular disease; $L V H=$ left ventricular hypertrophy; $R B B B=$ right bundle-branch block; LASH=left anterior superior hemiblock; FRP-AVN=AV nodal functional refractory period; ERP-AVN $=A V$ nodal effective refractory period; FRP-A =atrial functional refractory period; $E R P-A=$ atrial effective refractory period; $\mathrm{S}=$ slow pathway $; \mathrm{F}=$ fast pathway.

anomalous pathway conduction) during right ventricular pacing, as manifested by appropriate increases in VA conduction times with increasing pacing rates ( 10 beats/ min increments) and also during coupled ventricular stimulation. Group 2 included 4 patients with documented reproducible dual pathway AV nodal re-entrant paroxysmal supraventricular tachycardia (PSVT). These patients fulfilled criteria previously described by our laboratory (Denes et al., 1973). Clinical and electrophysiological data concerning all patients are presented in Table 1.

All patients were studied in the postabsorptive, nonsedated state. Informed consent was obtained in all patients. All drugs were discontinued 48 hours before the study. A tripolar electrode catheter was introduced percutaneously into the right femoral vein and placed across the tricuspid valve to record His bundle and low septal right atrial electrograms (Scherlag et al., 1969). A quadripolar electrode catheter was introduced into the left femoral vein, advanced into the high lateral right atrium, and positioned at the superior vena caval right atrial junction. The two distal pairs of electrodes were used for atrial pacing and the two proximal electrodes to record high right atrial electrograms. A bipolar electrode catheter, introduced via a right antecubital vein, was positioned in the distal coronary sinus to record posteroinferior left atrial electrograms. The position of the catheter in the coronary sinus was confirmed by its posterior location in the lateral view and by the presence of inverted $P$ waves in leads II and III during stimulation. In addition, a 5F bipolar electrode was introduced through the same antecubital vein and positioned at the right ventricular apex for ventricular pacing. Bipolar interelectrode distance for all catheters was $1 \mathrm{~cm}$.

Refractory periods were determined using the extrastimulus technique (Wit et al., 1970). Stimuli were 2 ms in duration and twice diastolic threshold in intensity, and supplied by a digital programmable pulse generator ${ }^{1}$. Intracardiac electrograms, including high right atrium (HRA) and coronary sinus (CS), as well as electrocardiographic standard leads I, II, III, and chest lead V1, were stimultaneously displayed on an oscilloscope and recorded on a multichannel photographic recorder ${ }^{2}$ at paper speeds of 100 and $200 \mathrm{~mm} / \mathrm{s}$.

\section{Electrophysiological definitions}

Previous definitions of PA, AH (LSRA-H), and HV intervals, as well as AV nodal functional and effective refractory periods (FRP and ERP) were used (Denes et al., 1974). $\mathrm{HRA}_{1}, \mathrm{LSRA}_{1}, \mathrm{CS}_{1}, \mathrm{H}_{1}$, and $\mathrm{V}_{1}$ were, respectively, high right atrial, low septal right atrial, coronary sinus, His bundle, and ventricular electrograms of the sinus or driven beats $\left(S_{1}\right) . H_{2} A_{2}$, LSRA, $\mathrm{CS}_{2}, \mathrm{H}_{2}$, and $\mathrm{V}_{2}$ were electrograms in response to the extrastimulus $\left(\mathbf{S}_{2}\right)$.

\section{Procedure}

Group 1 patients 1) The antegrade sequence of atrial activation was mapped during sinus rhythm and the following intervals measured: a) P-HRA: from the beginning of the $P$ wave in the electrocardiographic leads to the high right atrial electrogram. b) P-LSRA: from

${ }^{1} \mathrm{M}$. Bloom, Philadelphia, Pa.

2Electronics for Medicine DR-16, White Plains, New York. 
the beginning of the $\mathbf{P}$ wave to the low septal right atrial electrogram. c) P-CS: from the beginning of the $P$ wave to the coronary sinus electrogram. d) $\mathrm{P}-\mathrm{H}$ : from the beginning of the $P$ wave to the His bundle electrogram.

2) The right atrium (RA) was paced at rates slightly faster than sinus rhythm and then increased in 10 beats/min increments until AV nodal Wenckebach periods resulted.

3) The right ventricle (RV) was paced at rates slightly above the control sinus rate to ensure constant retrograde conduction, and the rate was then increased in 10 beat/min increments until retrograde Wenckebach periods were noted.

4) Ventriculoatrial conduction times (VA) were measured from the ventricular stimulus artefact to the first high frequency potential of the LSRA electrogram. $\triangle$ VA time was defined as the difference in VA conduction times obtained by pacing the RV at rates slightly above spontaneous sinus rate and those obtained at a rate slightly slower than that producing retrograde Wenckebach periodicity.

5) The retrograde sequence of atrial activation was mapped during 1:1 right-ventricular pacing and during coupled ventricular pacing at cycle lengths of 600-900 ms. The following intervals were measured: a) S-LSRA: from the stimulus artefact to the first high frequency deflection of the low septal right atrial electrogram. b) S-CS: from the stimulus artefact to the coronary sinus electrogram. c) S-HRA: from the stimulus artefact to the high right atrial electrogram. In two of the patients, in addition to distal coronary sinus, we also mapped the proximal coronary sinus. The latency between the stimulus artefact and the ventricular electrogram was insignificant in all cases. For purposes of analysis, the retrograde atrial activation sequence was measured at a paced ventricular cycle length of $600 \mathrm{~ms}$ (100 beats/min) in all patients.

In group 2 patients, in addition to the above procedure, the retrograde sequence of atrial activation was studied during episodes of induced paroxysmal supraventricular tachycardia, and the following intervals were measured: a) V-LSRA: from the onset of ventricular depolarization in the surface electrocardiogram to the first high frequency potential of the low septal right atrial electrogram. This interval could have a negative value in those cases where LSRA preceded the onset of the QRS. b) V-CS : from the onset of ventricular depolarization on the surface electrocardiogram to the onset of ventricular depolarization to the first high frequency potential in the high right atrial electrogram. V-HRA: from the onset of ventricular depolarization to the first high frequency potential in the high right atrial electrogram. All intervals represent the averate of 10 beats.

\section{Results}

Antegrade sequence of atrial activation Individual values, as well as mean values for P-HRA, P-LSRA, P-CS, and P-H for both groups 1 and 2 are presented in Table 2 . In every patient, the sequence of antegrade atrial activation was as follows: HRA, LSRA, and then CS.

\section{Retrograde atrial activation sequences}

During right ventricular pacing with 1:1 VA conduction, a consistent pattern of retrograde atrial activation was observed in both groups (Fig. 1, Table 3). In all patients except one, the sequence of retrograde atrial activation was as follows: low septal right atrium, coronary sinus, and high right atrium. In the one exception (Case 12), high right atrium slightly preceded coronary sinus. In the 2 patients in whom proximal coronary sinus was also mapped, this followed low septal right atrium by 10

TABLE 2 Antegrade conduction times during sinus rhythm (ms)

\begin{tabular}{|c|c|c|c|c|c|}
\hline Case No. & $P-H R A$ & $P-L S R A$ & $P-C S$ & $P-H$ & $W$ (beats/min) \\
\hline \multicolumn{6}{|l|}{ Group 1} \\
\hline 1 & 12 & 38 & 70 & 130 & 110 \\
\hline 2 & 13 & 45 & 80 & 124 & 150 \\
\hline 3 & 25 & 42 & 96 & 138 & 120 \\
\hline 4 & 13 & 34 & 78 & 123 & 180 \\
\hline 5 & 12 & 35 & 71 & 122 & 220 \\
\hline 6 & 18 & 43 & 85 & 163 & 150 \\
\hline 7 & 15 & 42 & 74 & 118 & 190 \\
\hline 8 & 15 & 59 & 94 & 204 & 120 \\
\hline Mean \pm SEM & $15 \pm 2$ & $42 \pm 2 \cdot 8$ & $81 \pm 3 \cdot 5$ & $140 \pm 10.4$ & $155 \pm 13.8$ \\
\hline \multicolumn{6}{|l|}{ Group 2} \\
\hline 9 & 10 & 41 & 57 & 99 & 180 \\
\hline 10 & 5 & 26 & 89 & 148 & 160 \\
\hline 11 & 19 & 40 & 98 & 127 & 170 \\
\hline 12 & 15 & 50 & 80 & 141 & 190 \\
\hline Mean \pm SEM & $12 \pm 3$ & $39 \pm 5$ & $81 \pm 8 \cdot 8$ & $128 \pm 11$ & $175 \pm 6.4$ \\
\hline
\end{tabular}

Abbreviations : See text for definition of P-HRA, P-LSRA, P-CS, and P-H. W=Paced rate producing AV nodal Wenckebach periods. 


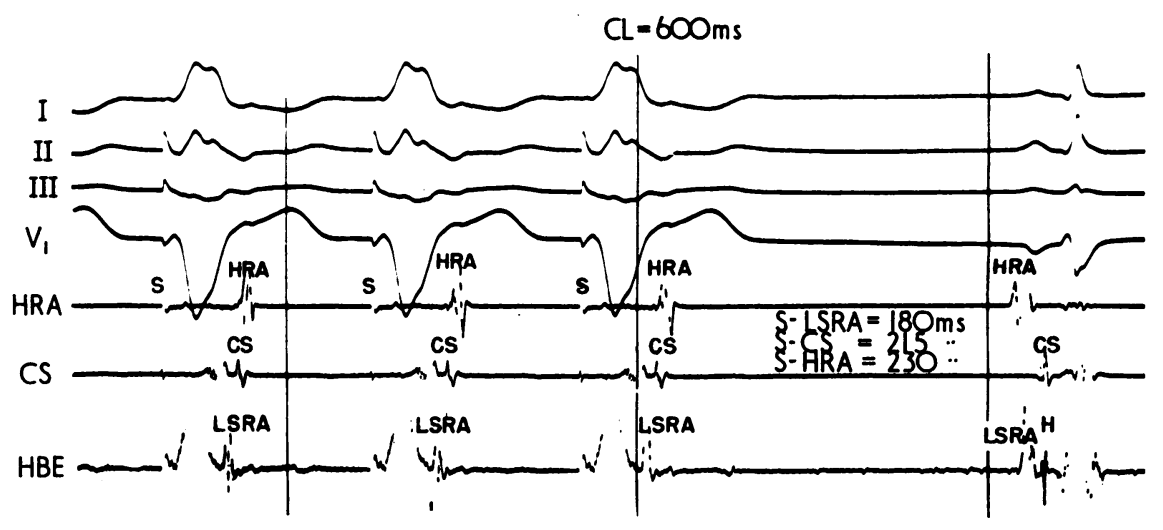

FIG. 1 Case 4. Retrograde atrial activation sequence during right ventricular pacing at cycle length of $600 \mathrm{~ms}$ (100 beats/min). Shown are leads I, II, III, and V1. HRA = high right atrial electrogram; $C S=$ coronary sinus electrogram; $L S R A=$ low septal right atrial electrogram; $S=$ stimulus artefact. In this and subsequent illustrations, paper speed was $100 \mathrm{~mm} / \mathrm{s}$, and time lines are at $1 \mathrm{~s}$.

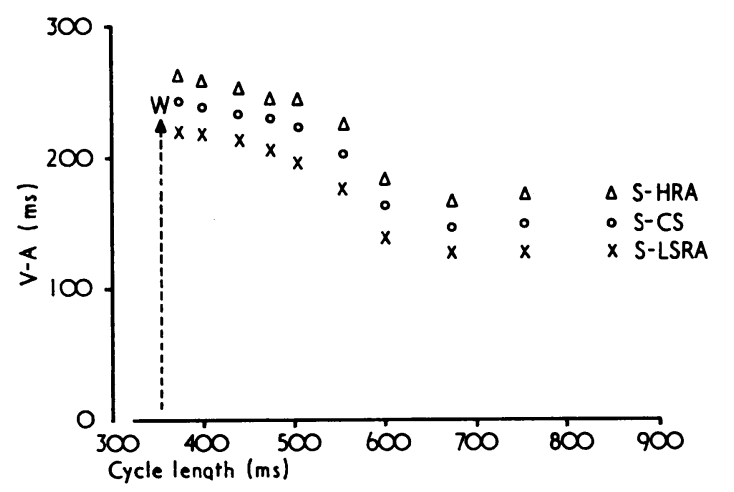

FIG. 2 Case 6. The retrograde atrial activation sequence during right ventricular pacing at increasing rates is shown. The VA conduction time is represented on the ordinate in ms. The cycle length of ventricular pacing is expressed on the abscissa. Note that the sequence of activation LSRA-CS-HRA does not change with increasing pacing rates.

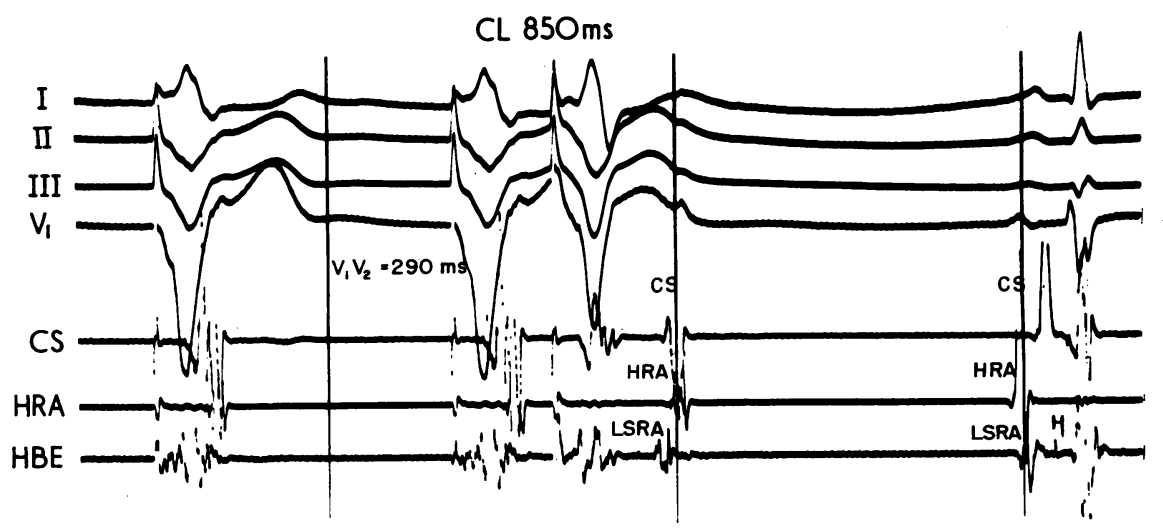

FIG. 3 Case 6. Coupled right ventricular pacing at cycle length of $850 \mathrm{~ms}$. Note that at $V_{1} V_{2}$ of $290 \mathrm{~ms}$, the retrograde atrial activation sequence is identical to the basic driving rate. 


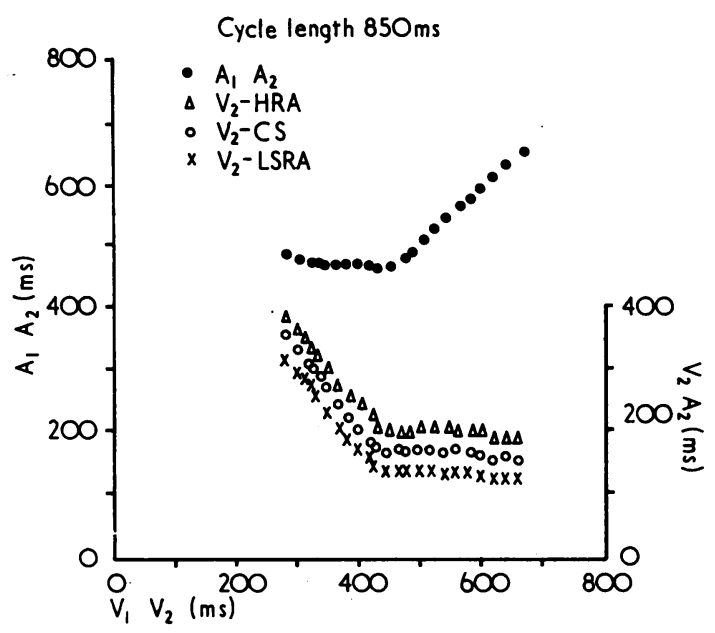

FIG. 4 Case 6. Coupled right ventricular pacing at cycle length of $850 \mathrm{~ms}$. On the left (ordinate), $A_{1}-A_{2}$ is plotted against $V_{1} V_{2}$. On the right (ordinate), $V_{2} A_{2}$ is plotted against $V_{1} V_{2}$. Note that the retrograde atrial activation sequence remains similar, despite appropriate increases in $V_{2} A_{2}$.

and $15 \mathrm{~ms}$, and preceded distal coronary sinus by 40 and $30 \mathrm{~ms}$, respectively.

The retrograde atrial activation sequence did not change with ventricular pacing at increasing rates. An example is shown in Fig. 2. VA conduction times were plotted against right ventricular pacing rates (expressed in cycle length). The right ventricle was paced at 70 beats $/ \mathrm{min}$, and then in 10 beats $/ \mathrm{min}$ increments until retrograde Wenckebach resulted at a rate of 170 beats $/ \mathrm{min}$. The VA time remained unchanged until $670 \mathrm{~ms}$ (rate of $90 / \mathrm{min}$ ) and then increased progressively up to the point of retrograde Wenckebach. The sequence of retrograde atrial activation remains unaltered at all pacing rates.

The retrograde sequence of atrial activation was also analysed during right ventricular coupled stimulation. Fig. 3 and 4 are representative examples. Activation sequences remained unchanged, despite appropriate increases in $V_{2}-A_{2}$.

\section{Retrograde sequence of atrial activation during paroxysmal supraventricular tachycardia}

The low septal right atrium was activated earliest during induced episodes of paroxysmal supraventricular tachycardia in all patients (Fig. 5 and Table $4)$. In 3 of the 4 patients, coronary sinus electrograms preceded high right atrial electrograms. In one patient (Case 12), the high right atrial electrogram preceded the coronary sinus electrogram by $2 \mathrm{~ms}$.

\section{Discussion}

The human heart is frequently capable of retrograde conduction. This ability has been demonstrated during spontaneous junctional (Puech and Grolleau, 1972; Damato and Lau, 1969) and ventricular rhythms (Winternitz and Langendorf, 1944; Kistin and Landowne, 1951; Kistin, 1961), and during electrophysiological studies using ventricular pacing (Damato, Lau, and Bobb, 1970; Goldreyer and Bigger, 1970). The reported frequency of ability for retrograde conduction has varied from 8 to 94 per cent (Samet, Castillo, and Bernstein,

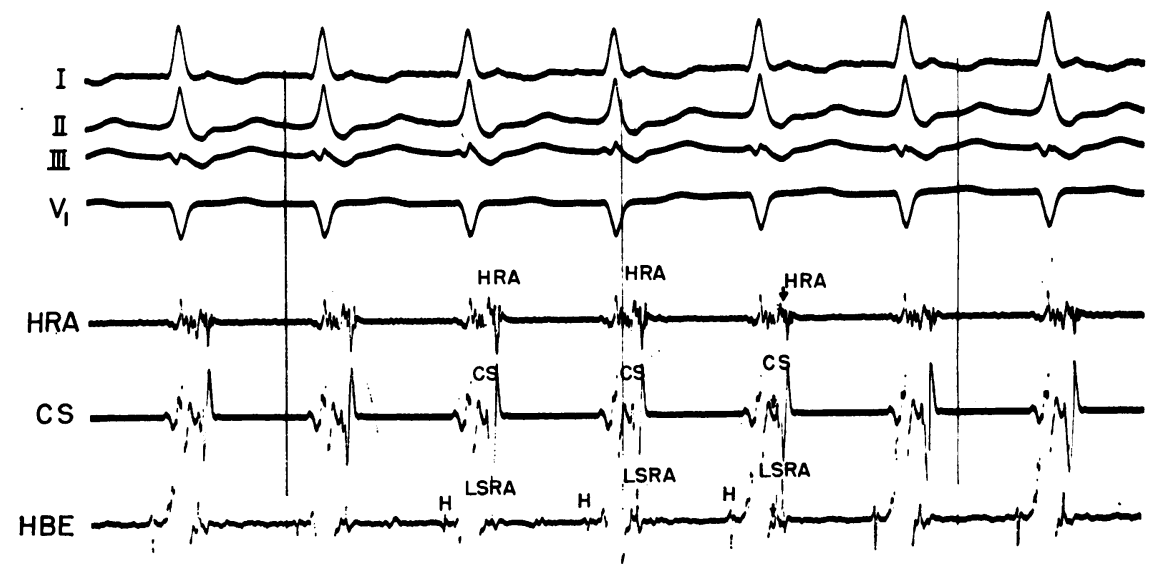

FIG. 5 Case 10. Retrograde atrial activation sequence during induced AV nodal re-entrant PSVT. Note that low septal right atrium (LSRA) precedes coronary sinus (CS) and high right atrium (HRA). 
TABLE 3 Retrograde conduction times (in ms) during ventricular pacing at cycle length of $600 \mathrm{~ms}$

\begin{tabular}{|c|c|c|c|c|c|}
\hline Case No. & $S-L S R A$ & $S-C S$ & $S-H R A$ & $\triangle V A$ & $W$ (beats/min) \\
\hline \multicolumn{6}{|l|}{ Group 1} \\
\hline 1 & 10) & 120 & 133 & 20 & 170 \\
\hline 2 & 135 & 163 & 185 & 25 & $18 J$ \\
\hline 3 & 155 & 169 & 199 & 30 & 180 \\
\hline 4 & 180 & 215 & 230 & 20 & 150 \\
\hline 5 & 175 & 216 & 222 & 20 & 153 \\
\hline 6 & 140 & 165 & 185 & 90 & 170 \\
\hline 7 & 230 & 253 & 285 & 25 & 140 \\
\hline 8 & 220 & 270 & 283 & 25 & 140 \\
\hline Mean \pm SEM & $167 \pm 15 \cdot 5$ & $196 \pm 17 \cdot 9$ & $216 \pm 17 \cdot 8$ & $32 \pm 8 \cdot 4$ & $160 \pm 6$ \\
\hline \multicolumn{6}{|l|}{ Group 2} \\
\hline 9 & 135 & 155 & 195 & 25 & 190 \\
\hline 10 & 220 & 232 & 252 & 45 & 150 \\
\hline 11 & 160 & 172 & 192 & 35 & 150 \\
\hline & 175 & 203 & 201 & 50 & 170 \\
\hline Mean \pm SEM & $172 \cdot 5 \pm 18$ & $190 \cdot 5 \pm 17$ & $210+14$ & $39+5 \cdot 5$ & $165 \pm 9 \cdot 6$ \\
\hline
\end{tabular}

Abbreviations: See text for definitions of S-LSRA, S-CS, S-HRA, and $\triangle \mathrm{VA} . \mathrm{W}=$ paced rate producing retrograde AV nodal Wenckebach periods.

1967; Kistin, 1961; Lister et al., 1967; Narula, 1974; Goldreyer and Bigger, 1970). The sequence of retrograde atrial activation in man has received less attention. Kraus, Yahini, and Neufeld (1966) using indirect pressure recordings from both atria, showed that the left atrium was activated first in one patient with premature ventricular contractions and intact VA conduction. Massumi et al. (1969) studied 18 patients with intact VA conduction during right ventricular pacing. In 11 patients, the right atrium was activated an average of $15 \mathrm{~ms}$ before the left atrium; in 6 patients, both atria depolarized almost simultaneously, and in one, the left atrium preceded the right atrium. During left ventricular pacing in 2 out of 3 patients, the left atrium was activated first. In their study (Massumi et al., 1969), a bipolar electrode catheter was used to explore the right atrium and an oesophageal bipolar electrode the left atrium. The location of the recording intracardiac electrodes was not precisely delineated. More recently, Svenson et al. (1974) reported on one patient without pre-excitation: during RV pacing, the low septal right atrial electro-

TABLE 4 Retrograde atrial activation sequence during PSVT (in $\mathrm{ms}$ )

\begin{tabular}{llll}
\hline Case No. & $V$-LSRA & $V$-CS & $V$-HRA \\
\hline 9 & -5 & 45 & 65 \\
10 & 70 & 85 & 100 \\
11 & 10 & 25 & 50 \\
12 & 75 & 98 & 96 \\
Mean \pm SEM & $36 \pm 20 \cdot 5$ & $63 \pm 17$ & $78 \pm 12 \cdot 1$
\end{tabular}

Abbreviations: See text for definitions of V-LSRA, V-CS, and V-HRA. gram preceded low lateral right atrium and lateral left atrium (recorded from the distal coronary sinus). This observation is in agreement with our findings, that in both groups of patients, low septal right atrial activation always preceded distal coronary sinus and high right atrial activation. The demonstration of early activation of the low septal right atrium is consistent with previous experimental observation in animals. Thus, Spach et al. (1971), studying the retrograde excitation sequence in isolated hearts of dogs and rabbits, found that initial atrial activation occurred in an area over the posteroinferior region of the AV node, and that from there, the wave front spread over the lower septum. Mignone and Wallace (1966), by mapping the endocardial surface of the right atrium in dogs with a bipolar probe electrode, found that during ventricular pacing with retrograde transmission, the earliest atrial activity was recorded near the ostium of the coronary sinus and approximately $1 \mathrm{~cm}$ above the AV ring; 3 to $12 \mathrm{~ms}$ later, atrial tissue at the region where a chronically His electrode was implanted was activated (LSRA). In dogs, Damato et al. (1970) studied the retrograde atrial mapping during $\mathrm{RV}$ or His bundle pacing, and found that the lower portion of the atrial septum was activated first, followed next by Bachman's bundle, the coronary sinus, and then the sinus node.

\section{Retrograde atrial activation during AV nodal re-entrant PSVT}

Current evidence suggests that the underlying mechanism of most paroxysmal supraventricular tachycardia is an intra-AV nodal circus movement caused by functional longitudinal dissociation 
(Denes et al., 1973; Wu and Denes, 1975). In most patients with AV nodal re-entrant paroxysmal tachycardia, AV nodal conduction curves $\left(A_{1}-A_{2}, H_{1}-H_{2}\right)$ are discontinuous, suggesting dual AV nodal pathways. The 4 cases included in this study fulfilled the previously described criteria for dual AV nodal pathway re-entrant paroxysmal tachycardia (Denes et al., 1973; Wu et al., 1974).

There is little information concerning the sequence of atrial activation during AV nodal reentrant paroxysmal supraventricular tachycardia. Experimental animal studies suggest a site of reentrance in the AN region of the AV node (Janse et al., 1971). One might, thus, expect the atria to be activated in a similar fashion to that occurring during retrograde conduction from the ventricle. In the 4 cases of AV nodal re-entrant paroxysmal tachycardia reported in this series, this was so: in each of the 4 cases, retrograde activation of the atria was identical during both ventricular pacing with retrograde conduction and during induced episodes of paroxysmal tachycardia. It is also noteworthy that these activation sequences were similar to those seen in the 8 patients without paroxysmal supraventricular tachycardia.

\section{Clinical implications}

In this study, we have shown the following sequence of retrograde activation during both ventricular pacing and during AV nodal re-entrant paroxysmal supraventricular tachycardia: 1) low septal right atrium, 2) coronary sinus, and 3) high right atrium. The finding of a retrograde activation sequence different from the above suggests the presence of an anomalous connexion between ventricles and atria. For example, early activation of the coronary sinus suggests the presence of a left-sided anomalous pathway. Though low lateral right atrial electrograms were not recorded during this study, it seems reasonable to postulate that early activation of the low lateral right atrium (relative to the low septal right atrium) would reflect the presence of a lateral right-sided extranodal pathway.

In a patient with recurrent paroxysmal supraventricular tachycardia, it seems crucial to record retrograde activation sequences during induced episodes of tachycardia. The presence of an abnormal retrograde activation sequence suggests the participation of a retrogradely conducting anomalous pathway in an AV re-entrant circus movement. In a patient with manifest antegrade preexcitation, the circus movement would generally be consistent with the electrocardiographically predicted site of anomalous pathway, e.g. early activation of coronary sinus in a patient with type $A$ pre-excitation. The finding of early activation of the atrium contralateral to the predicted site of preexcitation, e.g. early activation of the coronary sinus in a patient with type B pre-excitation, could suggest the presence of a second anomalous pathway used for retrograde conduction (Spurrell, Krikler, and Sowton, 1974b; Denes et al., 1975). The presence of an abnormal retrograde activation sequence in a patient without manifest antegrade pre-excitation suggests the presence of a concealed (unidirectionally conducting) Kent bundle (Spurrell et al., 1974a; Zipes et al., 1974a).

These considerations seem vital when considering a patient for anomalous pathway ablation, because of recurrent paroxysmal supraventricular tachycardia.

\section{References}

Coumel, P., and Attuel, P. (1974). Reciprocating tachycardia in overt and latent preexcitation. European fournal of Cardiology, 1, 423.

Damato, A. N., and Lau, S. H. (1969). His bundle rhythm. Circulation, 40, 527.

Damato, A. N., Lau, S. H., and Bobb, G. A. (1970). Studies on ventriculo-atrial conduction and the reentry phenomenon. Circulation, 41, 423.

Denes, P., Amat-y-Leon, F., Wyndham, C., Wu, D., Levitsky, S., and Rosen, K. M. (1976). Electrophysiological demonstration of bilateral anomalous pathway in a patient with type B preexcitation. American fournal of Cardiology, $1,93$.

Denes, P., Wu, D., Dhingra, R. C., Chuquimia, R., and Rosen, K. M. (1973). Demonstration of dual A-V nodal pathways in patients with paroxysmal supraventricular tachycardia. Circulation, 48, 549.

Denes, P., Wu, D., Dhingra, R., Pietras, R. J., and Rosen, K. M. (1974). The effects of cycle length on cardiac refractory periods in man. Circulation, 49, 32.

Durrer, D., and Wellens, H. J. (1974). The Wolff-ParkinsonWhite syndrome, anno 1973. European fournal of Cardio$\log y, 1,347$.

Gallagher, J. J., Gilbert, M., Svenson, R. H., Sealy, W. C., Kasell, J., and Wallace, A. G. (1975). Wolff-ParkinsonWhite syndrome. The problem, evaluation, and surgical correction. Circulation, 51, 767.

Goldreyer, B. N., and Bigger, J. T. (1970). Ventriculo-atrial conduction in man. Circulation, 41, 935.

Janse, M. J., Van Capelle, F. J. L., Freud, G. E., and Durrer, D. (1971). Circus movement within the AV node as a basis for supraventricular tachycardia as shown by multiple microelectrode recordings in the isolated rabbit heart. Circulation Research, 28, 403.

Kistin, A. D. (1961). Retrograde conduction to the atria in ventricular tachycardia. Circulation, 24, 236.

Kistin, A. D., and Landowne, M. (1951). Retrograde conduction from premature ventricular contractions, a common occurence in the human heart. Circulation, 3, 738.

Kraus, Y., Yahini, J. H., and Neufeld, H. N. (1966). Retrograde activation of the left atrium. Israel fournal of Medical Sciences, 2, 350.

Lister, J. W., Delman, A. J., Stein, E., Grunwald, R., and Robinson, G. (1967). The dominant pacemaker of the human heart. Antegrade and retrograde activation of the heart. Circulation, 35, 22. 
Massumi, R. A., Savin, R. K., Tawakkol, A. A., Rios, J. C., and Jackson, H. (1969). Time sequence of right and left atrial depolarization as a guide to the origin of the $P$ waves. American fournal of Cardiology, 24, 28.

Mignone, R. J., and Wallace, A. G. (1966). Ventricular echoes. Evidence for dissociation of conduction and reentry within the AV node. Circulation Research, 19, 638.

Narula, O. S. (1974). Retrograde pre-excitation. Comparison of antegrade and retrograde conduction intervals in man. Circulation, 50, 1129.

Neuss, H., Schlepper, M., and Thorman, J. (1975). Analysis of re-entry mechanisms in three patients with concealed Wolff-Parkinson-White syndrome. Circulation, 51, 75.

Puech, P., and Grolleau, R. (1972). L'activité du Faiseau de His Normale et Pathologique. Sandoz Edition, Paris.

Samet, P., Castillo, C., and Bernstein, W. H. (1967). Studies in $\mathrm{P}$ wave synchronization. American fournal of Cardio$\log y, 19,207$.

Scherlag, B. J., Lau, S. H., Helfant, R. H., Berkowitz, W. D., Stein, E., and Damato, A. N. (1969). Catheter technique for recording His bundle activity in man. Circulation, 39, 13.

Spach, M. S., Lieberman, M., Scott, J. G., Barr, R. C., Johnson, E. A., and Kootsey, J. M. (1971). Excitation sequences of the atrial septum and the AV node in isolated hearts of the dog and rabbit. Circulation Research, 29, 156.

Spurrell, R. A. J., Krikler, D. M., and Sowton, E. (1974a). Concealed bypasses of the atrioventricular node in patients with paroxysmal supraventricular tachycardia revealed by intracardiac electrical stimulation and verapamil. American Fournal of Cardiology, 33, 590.

Spurrell, R. A. J., Krikler, D. M., and Sowton, E. (1974b). Retrograde invasion of the bundle branches producing aberration of the QRS complex during supraventricular tachycardia studied by programmed electrical stimulation. Circulation, 50, 487.

Svenson, R. H., Gallagher, J. J., Sealy, W. C., and Wallace, A. C. (1974). An electrophysiologic approach to the surgical treatment of the Wolff-Parkinson-White syndrome. Circulation, 49, 799.

Wellens, H. J. J. (1975). Contribution of cardiac pacing to our understanding of the Wolff-Parkinson-White syndrome. British Heart fournal, 37, 231.

Wellens, H. J., and Durrer, D. (1974). Pathway of tachycardia in WPW syndrome. Circulation, 50, Suppl. 3, 58.

Winternitz, M., and Langendorf, R. (1944). Auriculoventricular block with ventriculoauricular response. Report of six cases and critical review of the literature. American Heart fournal, 27, 301.

Wit, A. L., Weiss, M. B., Berkowitz, W. D., Rosen, K. M., Steiner, C., and Damato, A. N. (1970). Patterns of atrioventricular conduction in the human heart. Circulation Research, 27, 345.

Wu, D., and Denes, P. (1975). Mechanisms of paroxysmal supraventricular tachycardia. Archives of Internal Medicine, 135, 437.

Wu, D., Denes, P., Dhingra, R., Khan, A., and Rosen, K. M. (1974). The effects of propranolol on induction of $A-V$ nodal reentrant paroxysmal tachycardia. Circulation, 50, 665.

Zipes, D. P., DeJoseph, R. L., and Rothbaum, D. A. (1974). Unusual properties of accessory pathways. Circulation, 49, 1200.

Requests for reprints to Professor Kenneth M. Rosen, Section of Cardiology, University of Illinois Hospital, Box 6998, Chicago, Illinois 60680, U.S.A. 